\title{
Limitations of standard analytical methods of shaft liner design
}

\author{
N-A Hentrich $D M T G m b H \&$ Co. KG, Germany \\ DS Calderón DMT Geosciences Ltd., Canada \\ S Bock DMT GmbH \& Co. KG, Germany \\ J Franz DMT GmbH \& Co. KG, Germany
}

\begin{abstract}
Several technical standards for mine shaft lining design have been developed over the past century, especially in countries that have constructed a high number of underground mines. These standards apply different design approaches and consequently, provide the designer with different results. Based on analytical or empirical methods, they give guidance to dimension shaft liners under consideration of the effect of the main factors influencing their stress-strain state. In the engineering practice, such shaft lining design standards are often extended or complemented with other analytical methods, such as the convergence-confinement method, which evaluates the influence of the excavation process and the unsupported shaft section. This paper presents an overview of the most popular standards used for shaft lining design, comparing their consideration of various factors, such as the non-circularity of the shaft geometry, non-uniform lining load, anisotropic ground pressure, water pressure distribution, design life, temporary rock support, temperature load and different lining types. Furthermore, the limitations of these methods are discussed taking into account different approaches for groundwater control (e.g. ground freezing) or shaft sinking methodology (drill and blast, mechanised sinking etc.).
\end{abstract}

A case study is performed, in which the lining of the Victoria mine shaft is dimensioned according to three existing standards, obtaining a wide range of results. The applicability of these standards for this shaft is found to be limited.

Proposals are made regarding future work to further improve the shaft lining design, to also include the possibility of using numerical approaches and their compatibility with analytical standards.

Keywords: analytical, standards, DIN, SNIP, PN, shaft lining design, limitations

\section{Introduction}

Shafts provide access and ventilation to underground mines, which makes them an essential part of the mine's infrastructure. Therefore, the structural integrity of the shaft lining over its entire lifetime is required for a safe and uninterrupted mine operation. Consequently, shaft lining design and dimensioning is a matter of high interest. Several national standards, based on analytical and empirical methods, are available to the designer. Alternatively, commercial software packages relying on numerical methods have developed in the last decades and are now state-of-the-art in engineering design.

It appears to the authors that a comparative overview of the design approaches of the different standards would be useful. The standards are mandatory in their countries of origin, which could explain why a comparison between them has not been performed to date from the international perspective. The comparison is relevant because national standards differ in their methodology and also in the results that are derived from them. Moreover, each of these standards may be limited by their methodology to determined geological conditions, depths or lining types. 
To the authors' knowledge, there is only a reduced number of countries with their own specific standards for shaft lining. The shaft lining standards from Germany, Poland and Russia, which have been widely used over the past century, were considered in this paper.

\section{Description, comparison and limitations of the standards}

\subsection{Description of the standards}

\subsubsection{German Standard DIN 21500:2017-05: Shaft Sinking in Mining - Design and Dimensioning}

The standard DIN 21500:2017-05 (Deutsches Institute für Normung e.V. (DIN) 2017) is mandatory for shaft design in Germany. In addition, it serves as a worldwide reference for shaft lining design and has been used in other countries, such as Canada and Belgium. This standard is based on the Guidelines for Calculating Shaft Linings in Unstable Rocks (Steinkohlenbergbauverein 1985) and on the experience gained by experts over decades in the German mining industry, mainly in coal mining in the Ruhr region and in salt and potash mines.

The standard is completely adapted to the European standards (Eurocodes) EN 1990 to EN 1998 (European Committee for Standardization 1990, 1991, 1992, 1993, 1994, 1996, 1997, 1998) which are presented in section 2.1.2. The scope of application of the standard is defined as follows:

"This standard applies to designing and dimensioning load-bearing support construction for new and normally circular - cylindrical vertical shafts in mining in unstable and stable rocks (...)" DIN 21500:2017-05

A detailed guideline for shaft lining dimensioning and calculation is provided to the design engineer in this standard. A special feature of this standard is that the user has to consider a non-uniform horizontal pressure on the shaft lining in addition to other usual loads, such as ground pressure, water pressure, thermal loads or vertical loads. In line with the general philosophy of the Eurocodes, safety factors are applied on the material properties and on the loads.

Furthermore, the standard defines several input parameters which have to be provided by the user, such as the purpose and special requirements of the shaft, the ground, geology, hydrogeology and the ground pressure for which the shaft lining will be designed.

For the calculation of the ground pressure, DIN 21500:2017-05 suggests using the formula for planar ground pressure, but also gives the option of using another method like the spatial ground pressure.

\subsubsection{European Standards EN 1990 to EN 1998: Eurocodes}

The Eurocodes provide a common framework for the design of buildings and civil engineering structures applicable in most European countries. The intention of the Eurocodes is to have a common, global and comprehensive package of standards in the European Union to design buildings and other civil engineering structures. As such, these European standards are not specifically focused on dimensioning and designing deep mine shafts but can provide the design principles and a more general approach. The Eurocodes can be used for a general analysis of structural elements (such as steel, concrete, reinforced concrete etc.).

In principle, other European standards contradicting the Eurocodes are to be withdrawn or harmonised. This is the reason why the DIN 21500:2017-05 was adapted to the Eurocode framework in 2017. This German standard is still applicable and valid, due to its specific focus on the lining of deep mine shafts. Therefore, from this chapter on, the DIN 21500:2017-05 and the Eurocodes will be considered together, in a combined approach.

The Eurocodes package of standards is divided into nine main topics, eight of which are listed below:

- EN 1990 (Eurocode 0): Basis of Structural Design.

- EN 1991 (Eurocode 1): Actions on Structures.

- EN 1992 (Eurocode 2): Design of Concrete Structures. 
- EN 1993 (Eurocode 3): Design of Steel Structures.

- EN 1994 (Eurocode 4): Design of Composite Steel and Concrete Structures.

- EN 1996 (Eurocode 6): Design of Masonry Structures

- EN 1997 (Eurocode 7): Geotechnical Design.

- EN 1998 (Eurocode 8): Design of Structures for Earthquake Resistance.

The standards are adapted to each country by specific national annexes, which consider local conditions or experience.

\subsubsection{Polish Standards PN-G-05015 and PN-G-05016}

A similar shaft lining standard to the German one exists in Poland: the Polish standard PN-G-05015 (Polski Komitet Normalizacyjny (PKN) 1997a) which was originally published in 1979 and updated in the year 1997. This standard describes the general design of circular shaft linings. The calculation of the load on the liner, however, is described in another standard, PN-G-05016 (PKN 1997b). Both standards were published before the Eurocodes were finished; that is the reason why those standards are often not in line with the philosophy of the Eurocodes.

These standards provide the design engineer with a detailed description of the procedures to design different lining systems. The design philosophy is based mainly on experience of the mining industry in Poland, which results in several empirical coefficients. Furthermore, minimum lining thicknesses for various cases are fixed.

The calculation of liner load according to PN-G-05016 is divided into three basic stages:

1. Determination of basic parameters and coefficients of the rock mass.

2. Determination of the characteristic load on the liner with or without water pressure.

3. Determination of the design load on the liner.

For each of those stages, several safety factors are used:

- Factor of structural weakening of the rock, used as an extremely simplified transformation of laboratory rock properties into rock mass properties.

- Factor of load concentration due to the existence of other underground workings and shaft insets.

- Factor of load concentration resulting from the sinking method.

- Factor of load concentration resulting from neighbouring weak and strong strata.

- Factor of load increase resulting from non-horizontal inclination of geological strata.

- Factor of load changes according to the shaft diameter.

- Factor of load increase due to the greater shaft depth.

The partial factors defined in the PN-G-05016 result typically in a global safety factor of about two for a typical shaft of a diameter of $8 \mathrm{~m}$. However, additional factors need to be applied according to the standard PN-G-05015:

- Additional correction factor for various rock types, hydrogeological conditions and liner types.

- Additional safety factor for various liner types.

\subsubsection{Russian Standard SNIP II-94-80}

To standardise the standards in the Russian Federation, the Research Institute of Mining, Geomechanics and Mine Surveying in St Petersburg established the standard SNIP II-94-80 in 2013. 
The standard is mainly based on local, practical experience, which is combined with global safety factor philosophy. The global safety factor philosophy differs from the safety philosophy in the Eurocodes and is applied also in other Russian standards.

The calculating procedures are described in detail. Several empirical factors are introduced in the formulas, which are based on experience in the mining industry in the Russian Federation, in a manner similar to the Polish standard.

\subsection{Comparison between the standards}

Table 1 aims to give an overview of the main characteristics of the standards as well as the differences between the standards.

Table 1 General comparison of the standards

\begin{tabular}{lccc}
\hline & $\begin{array}{c}\text { DIN 21500 + } \\
\text { EN 1997-1 }\end{array}$ & $\begin{array}{c}\text { PN-G-05015/ } \\
\text { PN-G-05016 }\end{array}$ & SNIP II-94-80 \\
\hline Design philosophy & Analytical & Analytical/empirical & Analytical/empirical \\
Empirical coefficients & None & Several & Several \\
Detailed guideline & Relatively open & Detailed & Detailed \\
\hline
\end{tabular}

\subsection{Limitations}

The shaft lining standards presented in this paper were published with slightly different approaches. The specific geometrical and geological conditions and the construction sequence of the shaft have a large influence on the shaft lining loads and design. However, it is difficult to consider these effects using only analytical and empirical methods. In this respect, the limitations of the standards are condensed in Table 2 to evaluate the applicability of each standard in different cases.

Table 2 Limitations of the selected standards

\begin{tabular}{lccc}
\hline Factor influencing the lining design & $\begin{array}{c}\text { DIN 21500 + } \\
\text { EN 1997-1 }\end{array}$ & $\begin{array}{c}\text { PN-G-05015/ } \\
\text { PN-G-05016 }\end{array}$ & SNIP II-94-80 \\
\hline Non-circularity of shaft geometry & + & - & 0 \\
Non-uniform lining load & + & - & - \\
Anisotropic ground pressure & 0 & - & - \\
Water pressure distribution & + & + & + \\
Design life & 0 & - & 0 \\
Temporary rock support & - & - & - \\
Temperature load & + & - & - \\
Different lining types & + & + & + \\
Groundwater control & - & - & - \\
Nearby galleries/chambers & - & + & + \\
Unsupported height of shaft wall & - & 0 & 0 \\
\hline
\end{tabular}

' + ' - factor considered; ' $'-$ - factor not considered; ' 0 ' - factor could be considered with modifications. 


\section{Case study}

\subsection{Case description and input parameters}

The different design standards will be applied to an existing shaft in order to demonstrate the differences already described and how the choice of the standard has a major impact on the results, and consequently on the liner thickness.

For this case study, the authors selected the Victoria mine shaft in Canada, which was described with its liner design in the paper by Fabich et al. (2015).

The Victoria Mine site is located in Ontario, around $30 \mathrm{~km}$ from Sudbury. The construction of the shaft was started in 1900 and in 1918 the production shaft was successfully sunk to a depth of $918 \mathrm{~m}$. The mine then started copper and nickel production. The mine was flooded in 1923 and was closed until 1973. In the following years, the production of copper and nickel occurred and in 1978 the mine was closed again and flooded. The shaft has been closed until today. In 2011, new plans emerged to access the orebody again with a new shaft. The new shaft was designed with an inner diameter of $7.6 \mathrm{~m}$ and a final depth of $1,861 \mathrm{~m}$, with shaft stations every $300 \mathrm{~m}$ (Fabich et al. 2015).

The authors of the paper (Fabich et al. 2015) mentioned that the use of the Polish standard was not recommended for shaft design for a depth down to $1,850 \mathrm{~m}$. They remark that the formula of the standard considers only the virgin stresses resulting from the weight of the rock mass, but not other types of stresses, like those from tectonic origin. They also highlighted that neglecting such stresses can result in catastrophic consequences for the shaft design. Furthermore, they stated that the Polish standard was developed for mines which were normally constructed in Poland, with depths of less than 1,200 m (Fabich et al. 2015).

Fabich et al. (2015) calculated the design parameters by using the Hoek-Brown criterion and focused on the shaft section from $1,440 \mathrm{~m}$ to $1,851 \mathrm{~m}$ depth. They already advocated the use of modern numerical methods to design such deep shafts and they used a 2D-numerical program (Phase ${ }^{2}$ from Rocscience) for the design.

In the present paper, the known geology and boundary conditions are used to compare the standards for the $1,861 \mathrm{~m}$ deep shaft. The results obtained for the shaft lining dimensions consistent with the different standards are summarised in the next chapters.

The geometrical and geotechnical input parameters extracted from the paper (Fabich et al. 2015) are summarised in Table 3.

Table 3 Rock mass properties (Fabich et al. 2015)

\begin{tabular}{lccccc}
\hline & $\begin{array}{c}\text { Depth } \\
(\mathbf{m})\end{array}$ & $\begin{array}{c}\boldsymbol{\sigma}_{\mathrm{ci}} \\
(\mathrm{MPa})\end{array}$ & $\begin{array}{c}\mathbf{E}_{\mathrm{rm}} \\
(\mathbf{G P a})\end{array}$ & $\begin{array}{c}\mathbf{c} \\
(\mathrm{MPa})\end{array}$ & $\begin{array}{c}\boldsymbol{\phi} \\
\left({ }^{\circ}\right)\end{array}$ \\
\hline Metagabbro & $1,440.0$ & 35.5 & 35.8 & 10.46 & 48.1 \\
Metasediment & $1,675.5$ & 12.8 & 19.4 & 7.40 & 39.4 \\
Quartz-diabase & $1,785.0$ & 33.3 & 30.3 & 10.80 & 39.1 \\
\hline
\end{tabular}

A typical and relatively simple concrete liner was chosen to facilitate the comparison between the standards. A schematic figure of the ground pressure on a shaft liner is presented in Figure 1.

In an attempt to compare the three chosen standards with a method capable of considering the three-dimensional stress state during shaft sinking, the Convergence-Confinement Method (C-C) will be combined with the standards. It was assumed that the liner is to be constructed $5 \mathrm{~m}$ above the shaft excavation bottom. 


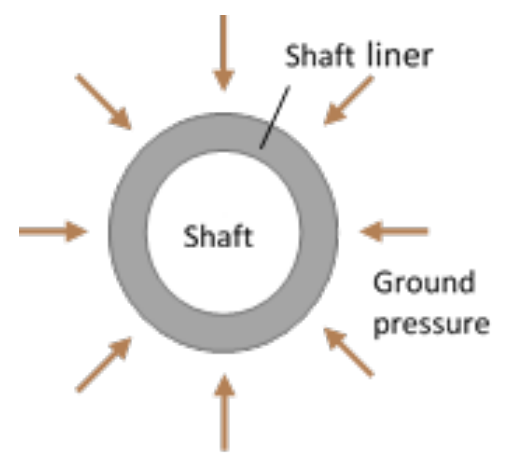

\section{Figure 1 Ground pressure on shaft liner}

The C-C-Method is an independent study of the ground and of the lining deformational behaviours. The ground behaviour is represented by a ground reaction curve (GRC) and the lining by a support reaction curve (SRC). The method describes the ground convergence in terms of the applied confining pressure and relates the confining pressure acting on the lining to its deformation. The solution is given by intersection of the two curves (Eisenstein \& Branco 1991; Carranza-Torres \& Fairhurst 2000).

Based on the case study the inner shaft diameter was set to $7.6 \mathrm{~m}$ and the depth of each layer was set as described in Table 3, for the calculation of the concrete thickness according to different standards, were used in general (unique input parameters are mentioned in the corresponding chapter, as they are required for the calculation).

\subsection{Calculations and results}

\subsubsection{German Standard DIN 21500:2017-05 and Eurocodes EN 1990 to EN 1998}

The German standard was modified several times during the last few decades of mining in Germany to fit the then current state-of-the-art design rules. The current version is adapted to the design philosophy of the Eurocode. The method for calculating the ground pressure is neither fixed in the DIN standard nor in the Eurocode, so the designer has to select the way to calculate the ground pressure. Moreover, the choice of the method to calculate the ground pressure has a significant influence on the results.

The calculation of the tangential stresses for a given load $p_{a}$ is made for the uniform and the non-uniform loads. The tangential stresses from the uniform and non-uniform loads can be calculated according to formulae from the DIN standard. The geometric parameters are defined in Figure 2.

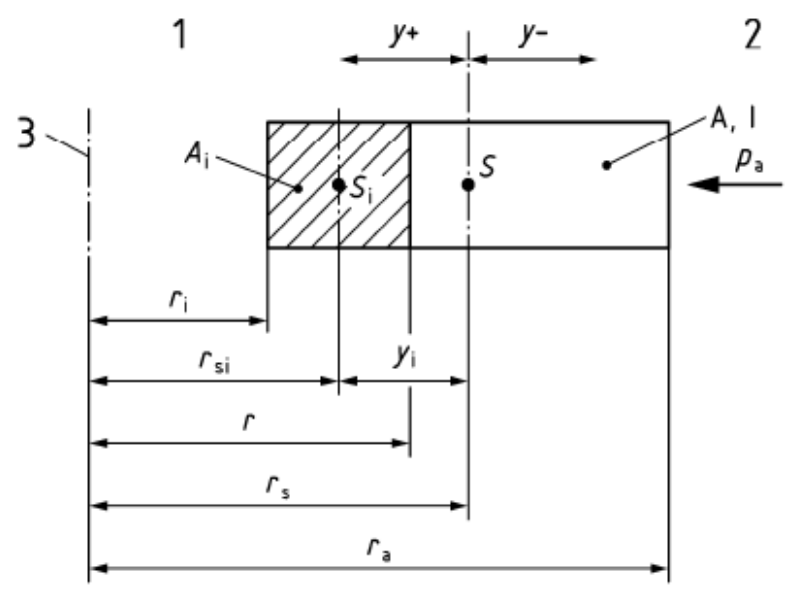

Figure 2 Geometric parameters for the calculation of the tangential, radial and shear stresses.

1 - Inside; 2 - Outside; 3 - Shaft axis 


$$
\begin{gathered}
\sigma_{t, \text { uniform }}=-\frac{p_{a} * r_{a}}{A} *\left(1+\frac{y}{r_{s}}\right) \\
\sigma_{t, \text { non-uniform }}=-\frac{1}{2} * \frac{p_{z} * r_{a}}{A}\left[\left(1+\frac{y_{i}}{r_{s}}\right)-\frac{1}{3} *\left(1+\frac{r_{s} * y}{i^{2}}\right) * \frac{W}{W-1} * \cos (2 \varphi)\right]
\end{gathered}
$$

where:

$$
\begin{array}{ll}
p_{a} & =\text { horizontal uniform ground pressure (MPa), see Table } 4 \\
p_{z} & =\text { peak value of the horizontal ground pressure (MPa) } \\
r_{a}, r_{s}, y, y_{i} & =\text { geometric values, see Figure } 2(\mathrm{~m}) \\
A & =\text { area of the cross-section of the liner }\left(\mathrm{m}^{2} / \mathrm{m}\right) \\
W & =\text { coefficient, calculated by Formula }(\mathrm{A} .10) \text { in DIN } 21500: 2017-05(-) \\
\mathrm{i} & =\text { inertia radius, refer to } 1 \mathrm{~m} \text { shaft height }(\mathrm{m} / \mathrm{m}) \\
\varphi & =\text { angular coordinate }\left({ }^{\circ}\right) \text {, Figure } 2 \text { in DIN } 21500: 2017-05, \text { see Table } 3 \\
& \sigma_{t, \text { total }}=\sigma_{t, \text { uniform }}+\sigma_{t, \text { non-uniform }}
\end{array}
$$

Based on the shown rock mass properties and the shaft geometry for the three exemplary formations the required concrete liner thicknesses were calculated. In Table 4 the input parameters for Equations 1 to 2 are given for the thinnest and thickest liner results.

Table 4 Input parameter for DIN 21500:2017

\begin{tabular}{lccccccccccc}
\hline Formation & $\begin{array}{c}\text { Calc. } \\
\text { method (-) }\end{array}$ & $\begin{array}{c}p_{a} \\
(\mathrm{MPa})\end{array}$ & $\begin{array}{c}p_{z} \\
(\mathrm{MPa})\end{array}$ & $\begin{array}{c}r_{a} \\
(\mathrm{~m})\end{array}$ & $\begin{array}{c}r_{s} \\
(\mathrm{~m})\end{array}$ & $\begin{array}{c}y \\
(\mathrm{~m})\end{array}$ & $\begin{array}{c}y_{i} \\
(\mathrm{~m})\end{array}$ & $\begin{array}{c}A \\
\left(\mathrm{~m}^{2} / \mathrm{m}\right)\end{array}$ & $\begin{array}{c}W \\
(-)\end{array}$ & $\begin{array}{c}\mathrm{i} \\
(\mathrm{m} / \mathrm{m})\end{array}$ & $\begin{array}{c}\varphi \\
\left({ }^{\circ}\right)\end{array}$ \\
Metasediment & $\begin{array}{c}\text { Planar- } \\
\text { active }\end{array}$ & 1.651 & 0.083 & 4.6 & 4.2 & 0.4 & 0.4 & 0.8 & 31.53 & 0.231 & 90 \\
Quartz-diabase & C-C & 6.228 & 0.311 & 5.4 & 4.6 & 0.8 & 0.8 & 1.6 & 56.12 & 0.462 & 90 \\
\hline
\end{tabular}

In Table 5 the results of Equations 1 to 3 are shown. Furthermore, the selected concrete class as well as the utilisation factor is mentioned. For the calculation of the required concrete class and the liner thickness, the standard reduces the concrete strength according to the Eurocode. The verification is performed dividing the concrete class by the maximum stresses in the concrete. That ratio should be lower than 1.

Table 5 Results of Equations 1 to 3, DIN 21500:2017

\begin{tabular}{lccccc}
\hline Formation & $\sigma_{t, \text { uniform }}$ & $\sigma_{t, \text { non-uniform }}$ & $\sigma_{t, \text { total }}$ & Concrete class & Utilisation factor \\
Metasediment & -12.5 & -2.9 & 15.4 & C30/37 & 0.91 \\
Quartz-diabase & -29.6 & -3.9 & 33.5 & C60/67 & 0.98 \\
\hline
\end{tabular}

As already described, the German standard does not fix the calculation method for the ground pressure. In order to exemplify the impact of the selection of the method on the lining thickness, the results using the planar-active ground pressure and the C-C-method are given in Table 4. An exemplary calculation of the ground pressure by the planar active ground pressure and the second mentioned option in the standard, the spatial ground pressure calculation gives calculated ground pressure values of $1.651 \mathrm{MPa}$ (planar-active) and $0.069 \mathrm{MPa}$ (spatial). This means the selection of the ground pressure calculation method is crucial.

The results differ to such an extent that the liner specifications are either very optimistic or very pessimistic. These results imply that it is highly recommended to investigate the actual ground pressure in detail and to verify it by means of in situ or laboratory tests. 


\subsubsection{Polish Standards PN-G-05015 and PN-G-05016}

The shaft liner design according to Polish standards is based on two standards: PN-G-05016 for calculation of the design horizontal load on the liner and PN-G-05015 for the calculation of the liner properties.

The two standards differ strongly. The first one, PN-G-05016, consists of many empirical equations and factors, which are defined differently for various load cases. It seems that the methodology of estimation of the liner load may be optimised and it appears to be a collection of additional updates and correction factors obtained during many years of experience from Polish shafts. In that way, different approaches are given for thin, weak geological layers, coal layers, water-bearing layers, non-cohesive strata etc.

The second standard mentioned, PN-G-05015, contains a straightforwardly described methodology for liner design of various lining types, among others:

- Concrete liner.

- Reinforced concrete liner.

- Brick liner.

- Tubbing liner.

- Two-columns liner.

For the purpose of comparison of the selected case, the thickness $d$ of the concrete liner is estimated as:

$$
d=a\left(\sqrt{\frac{R_{b b}}{R_{b b}-m \cdot p \cdot \sqrt{3}}}-1\right)
$$

where:

$$
\begin{aligned}
& \mathrm{d}=\text { thickness of the concrete liner }(\mathrm{m}) \text {. } \\
& a=\text { final radius of the shaft }(\mathrm{m}) \text {. } \\
& R_{b b}=\text { design concrete uniaxial compressive strength (MPa). } \\
& m=\text { correction factor depending on the geological strata, may vary between } 0.95 \text { and } 1.15(-) \text {. } \\
& p=\text { horizontal pressure obtained according to the PN-G-05016 (MPa), see Table } 4 .
\end{aligned}
$$

In Table 6 the input parameters for Equation 4 are given for two formations.

Table 6 Input parameter for PN-G-05015

\begin{tabular}{lcc}
\hline Concrete & $R_{b b}$ & $m$ \\
Unit & $(\mathrm{MPa})$ & $(-)$ \\
C30/37 & 13.90 & 1.10 \\
C50/60 & 22.50 & 1.10 \\
\hline
\end{tabular}

There are several equations to calculate the horizontal pressure according to the PN-G-05015. However, due to the uncomplete dataset, the standard allows to calculate the horizontal pressure using following equations:

$$
p=n_{H} \cdot n_{1} \cdot n_{2} \cdot n_{3} \cdot \sigma_{z \gamma} \cdot \tan ^{2}\left(45^{\circ}-\frac{\arctan \left(\frac{\sigma_{c i}}{10}\right)}{2}\right)
$$

where:

$$
\begin{aligned}
\sigma_{z \gamma} & =\text { vertical stress }(\mathrm{MPa}) . \\
n_{H} & =\text { correction factor for depth greater than } 800 \mathrm{~m} .
\end{aligned}
$$


$n_{1}=$ correction factor due to the existence of other underground workings and shaft insets.

$n_{2}=$ correction factor due to the non-horizontal inclination of geological strata.

$n_{3}=$ correction factor resulting from the shaft diameter:

$$
n_{3}=\frac{\sqrt[3]{D+1}}{2}
$$

The input parameters for the calculation of the horizontal pressure according to PN-G-05015 are presented in Table 7.

Table $7 \quad$ Input parameter for PN-G-05016

\begin{tabular}{lccccc} 
Formation & $n_{H}$ & $n_{1}$ & $n_{2}$ & $n_{3}$ & $\sigma_{z \gamma}$ \\
Unit & $(-)$ & $(-)$ & $(-)$ & $(-)$ & $(\mathrm{MPa})$ \\
Metagabbro & 1.1 & 1.0 & 1.0 & 1.04 & 35.9 \\
Metasediment & 1.1 & 1.0 & 1.0 & 1.04 & 40.6 \\
Quartz-diabase & 1.1 & 1.0 & 1.0 & 1.04 & 42.9 \\
\hline
\end{tabular}

\subsubsection{Russian Standard SNIP II-94-80}

The Russian standard SNIP II-94-80 is based on past experience, which was gained by the construction of many shafts in the last century.

Just a limited number of input parameters is required to use this standard. The main parameters are the depth of the formation, the uniaxial compressive strength of the rock mass and some general information about the situation, such as near shaft stations or neighbouring mining area.

To classify the rock mass, the Russian standard divides them and provides four different stability classes I to IV, with I as stable and IV as unstable. The stability class $C$ considers the depth of the calculated horizon $\left(H_{p}\right)$, as well as the uniaxial compressive strength of the rock mass $\left(R_{c}\right)$, and several empirical factors like lift coefficient $\left(k_{\Gamma}\right)$, nearby underground buildings $\left(k_{\mathrm{c} \sigma}\right)$, mining activities $\left(k_{\mathrm{L}}\right)$, and incidence angle of the layers $\left(k_{\alpha}\right)$. The stability class $\mathrm{C}$ can be calculated by the following formula:

$$
C=\frac{k_{\Gamma} k_{\mathrm{c} 5} k_{\mathrm{\amalg}} k_{t} H_{p}}{26,3+k_{\alpha} R_{C}\left(5.25+0,0056 k_{\alpha} R_{c}\right)}
$$

To calculate the ground pressure at the liner, the stability class defines the applicable formula. The stability class IV, which corresponds to unstable ground, is not covered by the standard. The Russian standard directs the user to a special authority or to an expert, who has to define the ground pressure. For the stability classes I to III the Russian standard provides a ground pressure formula.

The calculation of the monolith liner thickness, in this case a concrete liner, is performed as follows:

$$
\sigma_{k}=\Upsilon_{b} * r_{0} *\left(\sqrt{\frac{R \Pi p / \Upsilon_{m}}{R \Pi \mathrm{r} / \Upsilon_{m}-2 * \mathrm{Kp} * \mathrm{P}}}-1\right)-\delta п \mathrm{p}
$$

where:

$$
\begin{aligned}
\sigma_{k}= & \text { concrete liner thickness }(\mathrm{m}) . \\
\Upsilon_{b}= & \text { coefficient considering operation boundaries (-). } \\
r_{0}= & \text { final shaft radius }(\mathrm{m}) . \\
R \Pi p= & \text { calculated concrete strength (kPa) according to SNIP II 52-01-2003 (Research Institute of } \\
& \text { Mining Geomechanics and Mine Surveying 2003). } \\
\Upsilon_{m}= & \text { partial safety factor for concrete (SP63.13330) (-). }
\end{aligned}
$$




$$
\begin{aligned}
& \mathrm{Kp}=\text { coefficient to consider the stresses concentration in the liner }(-) . \\
& \mathrm{P} \quad=\text { horizontal pressure on the liner }(\mathrm{kPa}) \text {, see Table } 4 . \\
& \delta п \mathrm{p} \text {. coefficient for the penetration of the concrete into the nearby rock mass }(-) .
\end{aligned}
$$

The input parameters for the stability class are given in Table 8.

Table 8 Input parameters for the calculation of the stability class

\begin{tabular}{lcccccccc}
\hline Formation & $k_{\Gamma}$ & $k_{\mathrm{c} \sigma}$ & $k_{\mathrm{L}}$ & $k_{t}$ & $H_{p}$ & $k_{\alpha}$ & $R_{c}$ & $\mathrm{C}$ \\
Units & $(-)$ & $(-)$ & $(-)$ & $(-)$ & $(\mathrm{m})$ & $(-)$ & $(\mathrm{MPa})$ & $(-)$ \\
Metagabbro & 1.0 & 1.0 & 1.0 & 1.0 & 1440 & 1.0 & 35.5 & 6.553 \\
Quartz-diabase & 1.0 & 1.0 & 1.0 & 1.0 & 1785 & 1.0 & 33.3 & 8.609 \\
\hline
\end{tabular}

In Table 9 the input parameters as well as the result for the concrete liner thickness is given.

Table 9 Input parameters for the calculation of the concrete class

\begin{tabular}{lcccccccc}
\hline Formation & $\Upsilon_{b}$ & $r_{0}$ & $R \Pi p$ & $\Upsilon_{m}$ & $\kappa p$ & $\mathrm{P}$ & $\delta п р$ & $\sigma_{k}$ \\
Units & $(-)$ & $(\mathrm{m})$ & $(\mathrm{kPa})$ & $(-)$ & $(-)$ & $(\mathrm{kPa})$ & $(-)$ & $(\mathrm{m})$ \\
Metagabbro & 1.25 & 3.8 & $19.5(\mathrm{C} 25 / 30)$ & 1.0 & 1.0 & 0.3799 & 0.0 & 0.095 \\
Quartz-diabase & 1.25 & 3.8 & $37(\mathrm{C} 50 / 60)$ & 1.0 & 1.0 & 4.716 & 0.0 & 0.753 \\
\hline
\end{tabular}

\subsection{Comparison and limitations of the standards}

Based on the case study of the Victoria Mine in Canada (Fabich et al. 2015), which is planned to re-open and deepen to $1,851 \mathrm{~m}$, three common standards for deep shaft design were used to dimension a concrete liner.

The German standard is based on mathematical and theoretical derivations, which allows the designer to understand how every value must be calculated. However, the standard does not consider special cases, such as the effect of weak layers in the nearby environment or the impact of mining activities or drifts.

The Polish standard provides a highly complex calculation, which includes several aspects of mining, like weak layers, mining activities or other underground openings. Moreover, some empirical parameters are hard to follow up because they are based only on past experience.

The Russian standard is at first sight quite easy to use, but it contains many empirical parameters based on past experience, the origins of which are not explained. It is possible to apply the standard while having very little information of the shaft, which allows the pre-design of a shaft lining at a very early stage. Furthermore, the standard has some direct limitations for the designer, e.g. that a monolithic concrete liner should not exceed a thickness of $0.5 \mathrm{~m}$.

In Table 10 the results of the calculation of a monolith concrete liner by using the standards and by using the C-C Method is given.

Nevertheless, each standard is highly sensitive to the calculation of the load acting on the liner, as was shown in the calculations in section 3.2. Thus, it is highly recommended to verify as soon as possible the assumptions of the rock mass properties, the in situ stresses and the excavation sequence, all of which influence the loads induced on the shaft liner by ground pressure. The results for concrete liner thickness presented here allow to compare the three standards, however, the usability or constructability of the liners has not been considered in detail. As mentioned, in the Russian standard, the concrete thickness is limited to $500 \mathrm{~mm}$, which is exceeded in some cases. The German as well as the Polish standard have no limits in this way. Nevertheless, from a practical point of view, if the concrete thickness is more than $1.0 \mathrm{~m}$, an alternative liner system, which reduces the liner thickness overall, should be at least investigated. 
Table $10 \quad$ Calculation results

\begin{tabular}{llllllllc}
\hline & & \multicolumn{2}{c}{$\begin{array}{c}\text { Load } \\
\text { (MPa) }\end{array}$} & \multicolumn{2}{c}{ Concrete type } & \multicolumn{2}{c}{$\begin{array}{c}\text { Concrete thickness } \\
\text { (m) }\end{array}$} \\
& & & $\begin{array}{c}\text { Planar- } \\
\text { active }\end{array}$ & C-C & $\begin{array}{c}\text { Planar- } \\
\text { active }\end{array}$ & C-C & $\begin{array}{c}\text { Planar- } \\
\text { active }\end{array}$ & C-C \\
\hline DIN 21500 & Metagabbro & $5.101^{*}$ & 3.185 & C55/67 & C50/60 & 1.400 & 1.00 \\
& Metasediment & 1.651 & 2.947 & C30/37 & C50/60 & 0.800 & 0.85 \\
& Quartz-diabase & $6.228^{*}$ & 4.716 & C60/75 & C50/60 & 1.600 & 1.40 \\
\hline PN-G-05015 \& & Metagabbro & 0.784 & 3.185 & C30/37 & C50/60 & 0.490 & 0.50 \\
PN-G-05016 & Metasediment & 5.508 & 2.947 & C50/60 & C50/60 & 3.500 & 0.50 \\
& Quartz-diabase & 1.059 & 4.716 & C30/37 & C50/60 & 0.680 & 0.80 \\
\hline \multirow{2}{*}{ SNIP II 94-80 } & Metagabbro & 0.380 & 3.185 & C25/30 & C50/60 & 0.095 & $0.814^{* * *}$ \\
& Metasediment & $-{ }^{* *}$ & 2.947 & $-{ }^{* *}$ & C50/60 & $-{ }^{* *}$ & $0.738^{* * *}$ \\
& Quartz-diabase & 0.523 & 4.716 & C25/30 & C50/60 & 0.135 & $1.389^{* * *}$ \\
\hline
\end{tabular}

* Ground pressure reduction by the cohesion component exceeds the active ground pressure, thus the minimum ground pressure is used. ${ }^{* *}$ Layer was classified as class IV, thus the standard gives no formula for the calculation of the load. ${ }^{* * *}$ Thickness of the concrete liner exceeds the maximum concrete liner thickness of $0.5 \mathrm{~m}$ which is defined in the standard. C-C - Convergence-Confinement Method.

The case study presented here indicates that those standards are not applicable for such a deep shaft, probably because mining shafts in Europe are predominantly shallower than this one.

Figure 3 provides a graphical overview of the results obtained from the three standards. The resulting concrete liner thickness for each layer is shown, calculated according to the three standards, along with the variant with the C-C Method. For the sake of comparability, the concrete class was fixed to C50/60 for all variants of the C-C Method. For the variants with 'standard' the concrete class was not fixed. The liner thickness and concrete class resulting in using the standards as it is described.

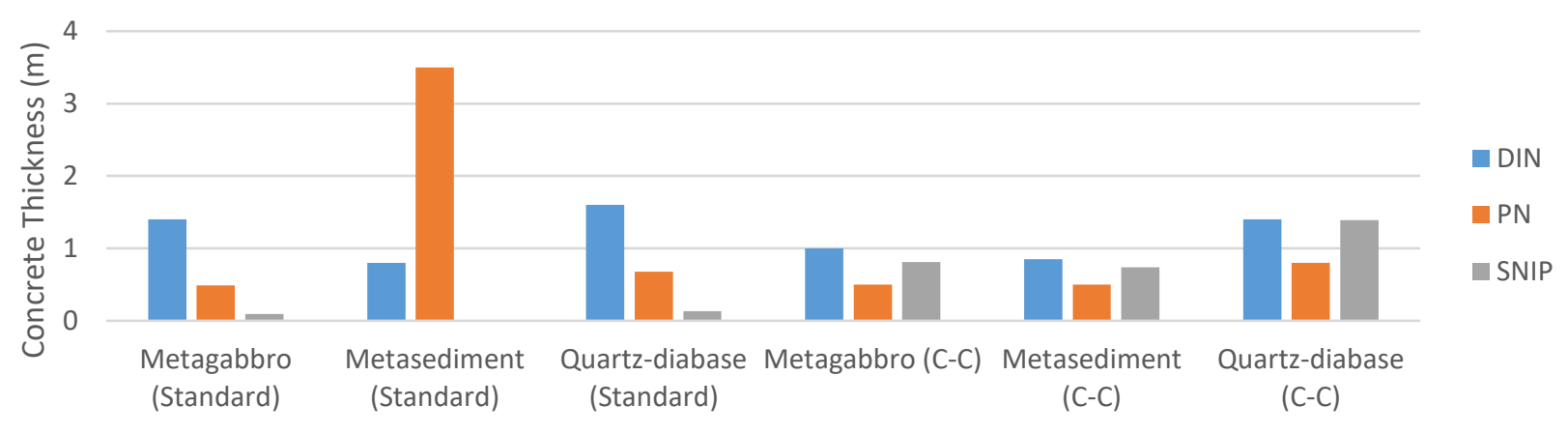

Figure 3 Comparison of the thickness of the monolithic concrete liner according to each standard and Convergence-Confinement Method (C-C)

It can be observed from Figure 2 that the calculated thickness of the monolithic concrete liner, without considering different concrete classes, varies widely. The resulting thickness of the concrete is very different even if the same load value is used as input parameter, like in the C-C Method. Taking the results of the DIN standard as $100 \%$, the thickness ranges to $50 \%$ of that value. As shown previously the Polish and Russian standards are based on several empirical factors in contrast to the German one. It is in the nature of empirical factors that they follow experience and history and cannot be recalculated by anyone who is not familiar with the history. Even minor changes in some factors have quite a significant input in the results. However, to investigate each empirical factor and the influence on the results was not the main focus of this paper. The 
results presented are significantly different to the numerical results of Fabich et al. (2015) which show a thin concrete layer with anchors. Consequently, the wide range of results in our case study as well as the results of Fabich et al. (2015) suggest that the use of numerical calculation methods is required for such deep shafts.

\section{Conclusion}

The paper has shown that there are major differences in the design philosophy of the three analysed standards: while the German standard proposes a design approach based on analytical calculations, the Polish and Russian standards rely on empirical factors. Moreover, the results of the case study differ widely: for instance, in the weakest sections (metasediment layer), the Polish standard would suggest a relatively thick concrete liner, while the Russian standard is not applicable.

The main challenge in applying the three standards during the proposed case study was found to be the correct calculation of the ground pressure. The standards come up with very different estimations of the loads induced by the ground pressure on the liner in such an extreme depth and strong rock mass. Moreover, as the German standard leaves the designer the choice of how to calculate the ground pressure, it delivers different results depending on the chosen calculated ground pressure. For the sake of an easier comparison, alternative calculations were performed calculating the ground pressure according to the C-C Method, using the same ground pressure for the three standards. Even in this case, the resulting liner thickness varies widely.

Therefore, it can be stated that the applicability of these standards should be restricted to geological conditions more similar to the ones for which they were conceived in their respective countries.

Another major limitation of the three standards is the fact that it becomes difficult to accurately determine the effect of several specific conditions, especially when complex, three-dimensional stress states exist, such as during the shaft sinking process or caused by nearby underground galleries.

Adequate procedures to calculate the ground pressure more accurately would be the C-C Method or numerical methods; the later are nowadays commonly used for detailed design of shaft linings.

\section{References}

Carranza-Torres, C \& Fairhurst, C 2000, 'Application of the Convergence-Confinement method of tunnel design to rock masses that satisfy the Hoek-Brown failure criterion, Tunnelling and Underground Space Technology, vol. 15, no. 2, pp. $188-213$.

Eisenstein, Z \& Branco, P 1991, 'Convergence-Confinement method in shallow tunnels', Tunnelling and Underground Space Technology, vol. 6, no. 3, pp. 343-346.

European Committee for Standardization, Eurocode 0 - Basis of Structural Design (EN 1990), European Committee for Standardization, Brussels.

European Committee for Standardization, Eurocode 1 - Actions on Structures (EN 1991), European Committee for Standardization, Brussels.

European Committee for Standardization, Eurocode 2 - Design of Concrete Structures (EN 1992), European Committee for Standardization, Brussels.

European Committee for Standardization, Eurocode 3 - Design of Steel Structures (EN 1993), European Committee for Standardization, Brussels.

European Committee for Standardization, Eurocode 4 - Design of Composite Steel and Concrete Structures (EN 1994), European Committee for Standardization, Brussels.

European Committee for Standardization, Eurocode 6, Design of Masonry Structures (EN 1996), European Committee for Standardization, Brussels.

European Committee for Standardization, Eurocode 7 - Geotechnical Design (EN 1997), European Committee for Standardization, Brussels.

European Committee for Standardization, Eurocode 8 - Design of Structures for Earthquake Resistance (EN 1998), European Committee for Standardization, Brussels.

Fabich, S, Bauer, J, Rajczakowksa, M \& Switon, S 2015, 'Design of the shaft lining and shaft stations for deep polymetallic ore deposits: Victoria mine case study', Mining Science, vol. 22, pp. 127-146.

Deutsches Institute für Normung e.V. (DIN) 2017, Shaft Sinking in Mining - Design and Dimensioning (DIN 21500:2017-05), Deutsches Institute für Normung e.V., Berlin.

Polski Komitet Normalizacyjny (PKN) 1997a, Szyby górnicze, Obudowa, Zasady projektowania (Mine shafts, Lining, Principles of designing) (PN-G-05015), Polski Komitet Normalizacyjny, Warsaw. 
Polski Komitet Normalizacyjny (PKN) 1997b, Szyby górnicze, Obudowa, Obciq̨żenia (Mine shafts, Lining, Loads) (PN-G-05016), Polski Komitet Normalizacyjny, Warsaw.

Research Institute of Mining Geomechanics and Mine Surveying 2003, Concrete and Won Concrete Construction - Design Requirements (SNIP II 52-01-2003), Research Institute of Mining Geomechanics and Mine Surveying - Interdisciplinary Scientific Center VNIMI JSC, Moscow.

Research Institute of Mining Geomechanics and Mine Surveying 2013, Underground mine workings (SNIP II-94-80), Research Institute of Mining Geomechanics and Mine Surveying - Interdisciplinary Scientific Center VNIMI JSC, Moscow.

Steinkohlenbergbauverein (coal mining association) 1985, Richtlinie zur Berechnung von Schachtauskleidung in nicht standfesten Gebirge (Guideline for the Calculation of Shaft Linings in Non-stable Rock Formations), 3rd edn., Verlag Glückauf, Essen 
